\title{
An Investigation into Requirement of Mobile App for Apartment Residents
}

\author{
Mohammad Shazreen Bin Haini", Chit Su Mon", Abdul Samad Bin Shibghatullah", \\ Abdurrahman Bin Jalil", Kasthuri A/P Subaramaniam", Amir Aatieff Amir Hussin \\ ${ }^{\#}$ School of IT, UCSI University, Cheras, WP Kuala Lumpur, 56000, Malaysia \\ E-mail:1001438086@student.ucsiuniversity.edu.my,chitsm@ucsiuniversity.edu.my,abdulsamad@ucsiuniversity.edu.my, \\ abdurrahman@ucsiuniversity.edu.my,kasthurisuba@ucsiuniversity.edu.my \\ *Kulliyyah of Information \& Communication Technology,International Islamic University Malaysia, Gombak, Malaysia. \\ E-mail: amiraatieff@iium.edu.my
}

\begin{abstract}
High-rise residential buildings, such as apartments, flats, and condominiums, are places of shelter for humans, just like any other types of houses. In a high-rise residential block, the building management plays a vital role in keeping the place pristine and habitable for its residents. Research shows that effective communication and harmonious relationship between the building management and the residents are crucial in maintaining a high-rise residential building. A solution needs to be proposed to alleviate this challenge. Traditionally, the mode of information dissemination and communication between the residents and the building management is done manually using information boards and feedback forms. However, their effectiveness, reliability and reachability are questionable. With the increasing adoption of mobile devices and cloud computing in today's scenario, the application of mobile technologies such as mobile applications has become viable as a solution to many real-world problems. This research studies how information about the happenings around the high-rise residential area is conveyed to the residents that is deemed as an essential part of the communication between the building management and the residents. This study aims to improve overall communication efficiency between the residents and the management parties of high-rise residential buildings by introducing a mobile app for apartment residents. Two data collection methods - observation and questionnaire - were used in this study and inspections were carried out in this research. Representations were made to investigate how the residents of a high-rise building receive information about happenings around the apartment complex and how the building management and residents committee communicate to share the information. The questionnaire survey was distributed to Facebook groups of high-rise residential buildings, particularly those staying in Sri Bahagia Court and Angkasa Condominium, as well as UCSI University network. Based on the results collected from participants, most of the communication was through physical noticeboard or online social media platforms such as Facebook. Hence, this research investigates the requirement of a mobile app and proposes the development of a mobile app for apartment residents (MyAPT), which addresses the problems of information sharing and further improves communication among the residents and management of high-rise buildings.
\end{abstract}

Keywords - apartments; residents; management; mobile app.

\section{INTRODUCTION}

High-rise residential properties consist of multiple-story units of individual houses built on a single, shared piece of land. In the Klang Valley, over $67.4 \%$ of high-rise residential buildings are non-low cost, which means they consist of medium-cost apartments and premium ones such as condominiums. The remaining are low-cost high-rise residential buildings such as flats [1]. Dwellers of these residential buildings share the same facilities and amenities such as 24-hour security, playground, covered parking, elevators, jogging tracks, etc., and these facilities are managed and maintained by the Joint Management Body or the Management Corporation of the residential building. Representatives of the residents of the building are usually elected annually to be of the Management Committee (MC) [2]. The function of these parties are legally bound as in the Strata Management Act 2013 and is enforced in every highrise residential property in Malaysia. Maintenance fees are collected monthly from the residents by the Management Corporation to be put into the management fund to keep the building and its facilities well-maintained and in working condition [3].

Healthy communication and relationship between the Management Corporation, Management Committee, and the residents of the building are crucial as these parties are 
responsible for taking care of the building together. As technology advances in communication and embedded technologies, such as mobile processors, chipsets, display, storage, memory, and other hardware designed for mobility, mobile phones have become as powerful as an ordinary personal computer [4]. Therefore, the use of mobile applications today is not just limited to caller, messenger, calculators, calendars - it can do more than that. Combined with Internet connectivity and other embedded sensors inside the phone, it benefits humankind in many ways such as enhancing daily tasks, enabling the sharing of information easily and allowing one to be connected to one another instantly. With a mobile application, communication between the residents, the Management Committee and the Management Corporation too can take place in a more efficient way. Common functions in mobile apps such as activity dashboards, push notifications, private messages, and more can be incorporated to make communications and participation between these parties more effective and thus improving the efficiency of each party in taking care of the building.

\section{A. Problem Statement}

1) Usage of Social Networking Sites (Facebook Groups): Social networking sites such as Facebook, Instagram, and Twitter have influenced most of people's daily life today. Take Facebook for example, as of 31 December 2017, its monthly active users have reached 2.13 billion people. Today, Facebook is not just a social networking website, it has more functions than that - and has become more convenient for the users, which explains its position as one of the top social networking websites to date [5]. Though features such as Facebook groups are useful to many, they do have drawbacks. As observed in the apartment resident's community, a closed group on Facebook is usually created for communication purposes. This group is not officially created and it has only a sole administrator and moderator. The administrator and members of the group consisting of members of the Management Committee and the residents, respectively. All of them use their personal Facebook profile.

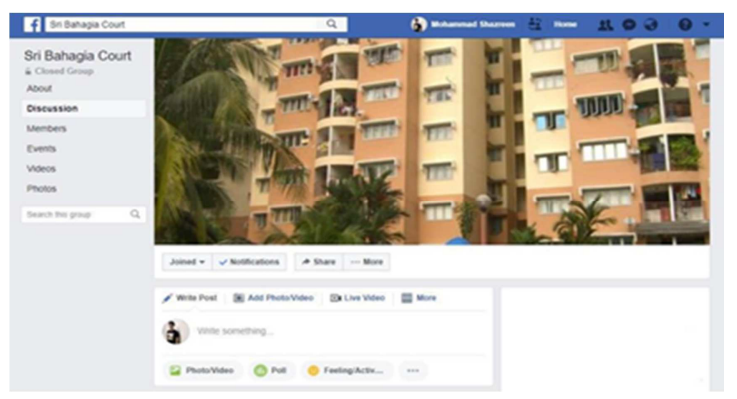

Fig.1 The Sri Bahagia Court Facebook Group

Any feedback or complaints made by posting in the group may pose a privacy issue as the complaint was made using a personal account, and there is no identification that the members are a dweller of the apartment. Note that these posts are displayed to all members and may include harsh complaints or words which may make other members in the group feel intimidated and tarnish someone's reputation. All the issues raised in the group will be taken care of by the administrator of the group, which is the member
Management Committee, and the progress of the status whether the issue has been resolved or not is visible unless specified. There should be a system whereby the communication between the residents and the management bodies can take place in a private, direct, and proper manner.

2) Reachability of Notices and Announcements: Another problem was that the announcements and notices made by the management office did not always reach all the residents. As discussed in the previous section, the current system causes inconvenience among residents as they must go to the ground floor to check out the noticeboard to know what is happening in their apartment. Not all notices or announcements are displayed on every level of the apartment.

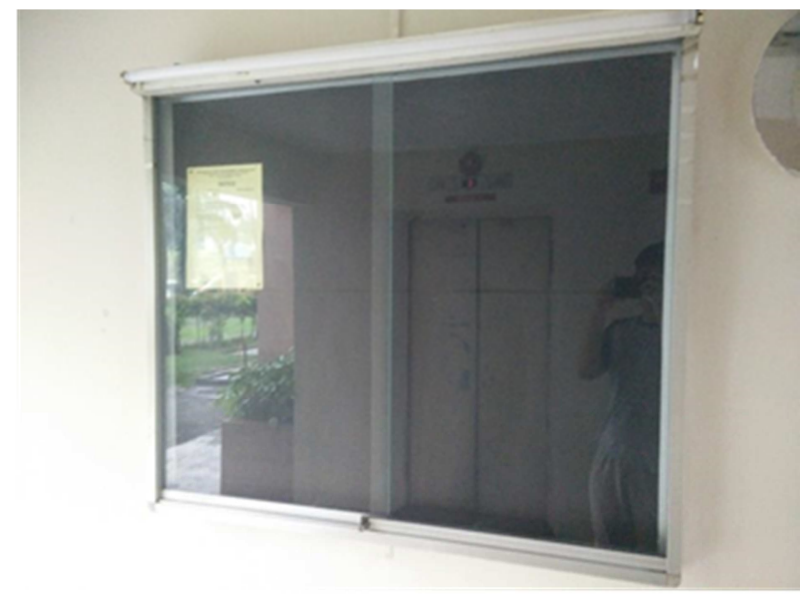

Fig.2 Noticeboard where announcements/notices are pinned.

Furthermore, if there is an urgent announcement made on the noticeboard, the residents may not be alerted to it. Some announcements such as grass cutting or pest fogging schedules may be overlooked by residents and caught unprepared. In addition, each year, the Management Corporation or Management Agent of the high-rise residential building is obligated to put out documents such as annual general meeting minutes and annual expenditure reports to be assessed by the residents. Currently, this is done by pinning the documents on the noticeboard page by page. Though it is physically displayed and one can request a copy from the management office, it can be inconvenient to those who want to read and evaluate the documents in detail. Hence, there should be a system where residents can get an important announcement and notice instantly.

\section{MATERIALS AND METHOD}

There were three main activities conducted in this study namely: (i) Literature Study (ii) Observation and (iii) Questionnaires. For the first activity, we reviewed previous researches based on the perspective of i. Facebook groups, social media purpose and effectiveness ii. Mobile Cloud Computing as well as iii. Mobile Push Notification. As for the second activity, the observation was carried out between April 2018 and July 2018 at one apartment in Cheras, Kuala Lumpur. The observation was done by observing how the residents of a high-rise residential building receive information about happenings around the apartment complex and how the building management and residents' committee 
disseminate information to the residents. Observation criteria were on the weaknesses in how the information was distributed to residents and its effects on the residents. The questionnaire is the last activity for collecting data and it can be widely distributed to people. The questions were set based on the online form creating a tool that is Google Forms. It is then distributed to Facebook groups of residents of high-rise residential buildings particularly Sri Bahagia Court and Angkasa Condominium, and UCSI University network on Course Networking LMS platform. During the distribution of the questionnaire, it was made clear that respondents should be residents of high-rise buildings.

\section{A. Literature Study}

1) Facebook groups, social media purpose, and effectiveness: Social media is indeed connecting us all. More functionalities have been added to social media platforms such as Facebook, Twitter, Instagram and LinkedIn from time to time. Facebook groups are one of the features that were added after its inception in 2007. Baruah [6] discussed the impact and effectiveness of social media as a communication tool medium and the potential of social media in 'technology-enabled connections. Research has been conducted involving the residents of Guwahati city in India. Most of the respondents agreed that social media is one of the major communication tools. They collectively agreed that social media has several advantages and disadvantages. Among the advantages are it is useful for idea sharing, communication tool and filling communication gaps. The disadvantages are privacy intrusion, risk of familial ties breakdown and reduced productivity. In a paper by Park et al, they conducted a web survey of 1,715 college students to identify the relation between the use of Facebook groups with offline social activities such as political and civic participation, and the needs of using Facebook groups. In this research, they have applied the use and gratifications theory. The data of their results shows that most of the students use Facebook groups mainly to get information about activities inside and outside the campus, socializing, and entertainment. The results show that Facebook groups' usage is mainly for entertainment and therefore, users are more inclined to do non-political social activities offline [7]. Further, Madge et al. [8] discuss the effectiveness of Facebook in formal teaching purposes. It is argued that students' perception of Facebook is mainly for socializing purposes and not for formal learning, though the latter is sometimes used informally. This research was carried out to find out how new students' got influenced to register on Facebook, how first-year undergraduate students used Facebook for socializing purposes while at the campus, and from the student perspective is there any role for social networking sites or social media used by the university to strengthen their social and academic integration. From their research conducted online with first-year undergraduate students in a specific university in the United Kingdom, they found that most of the respondents use Facebook to help them adapt to the campus environment, and the narrative of using Facebook mainly for socializing is more apparent. In the context of Facebook group effectiveness in e-learning environments, Chou et al find out whether learners of elearning are satisfied with the usage of Facebook Group for
Schools and whether they will continue to use it as an interactive e-learning environment. Their data is based on students who are taking the project management course, they were asked to join the Facebook group course and given a questionnaire at the end of the course. The results show most of the respondents agree that Facebook offers a good interface, is user-friendly, and ready for e-learning. Additionally, it is found that Facebook groups also provide a good environment for learners and instructors alike. The respondents also agree that they were satisfied and will continue to use Facebook Groups as e-learning support [9]. The effectiveness of Facebook Groups in the context of assisting academic progress is discussed by Melor et al. [10]. Their research is to find out whether Facebook groups are effective in teaching students writing skills and also improve students' writing skills. The data is collected from the Teaching of English as Second Language (TESL) Year 3 undergraduate students in Universiti Kebangsaan Malaysia (UKM). From the respondents, it is found that the Facebook group helps in brainstorming their ideas before writing. Similarly, in another research by $\mathrm{Ng}$ et al [11] in evaluating the perception on how Facebook groups discussion is effective in writing performance among college students, it is found that most of the respondents' attitude was positive on using Facebook group discussion. So far, the narratives and research on Facebook groups and social media effectiveness were positive and only on an educational perspective. Researches on the effectiveness of Facebook groups in building management and local neighborhood community are still lacking.

2) Mobile cloud computing: Cloud computing has certainly brought a significant benefit to how the online world works today. Scalability and ease of setup are major contributors to the adoption of cloud computing in the industry. However, as mobile device usage increases nowadays, the spotlight is now on mobile cloud computing. Qureshi et al made a critical overview of mobile cloud computing on how it is implemented and its challenges. It is found that mobile cloud computing consists of the cloud computing infrastructure provider serving mobile end-users and application developers via the Internet. Solutions brought by mobile cloud computing were also analyzed such as for general use of mobile cloud computing, offloading mobile computation, mobile cloud applications such as chat that requires storage and computing power, and elastic applications. Despite its solutions, the paper also discussed its limitations and issues. Limitations discussed such as mobile cloud computing was still limited to only Softwareas-a-Service (SaaS) while general cloud computing supports more service models. Besides, it is found that mobile cloud computing lacks standards that might lead to issues of unreliability and provider lock-in. Issues found were mainly around limitations of mobile devices in terms of its computation power in handling mobile cloud computing, network bandwidth constraint, network latency, network availability and security [12]. In a paper by Chetan et al., another detailed overview of mobile cloud computing was discussed. Similar to in [13], the paper discussed mobile cloud computing architecture, its issues and its advantages. In order to determine how the architecture works, the authors used an open-source mobile cloud platform Open mobster. 
Two entities were established in this architecture and they are the mobile cloud client and mobile cloud server. Challenges of mobile cloud computing were discussed, the issue found in [12] about lack of standards were also presented that possibly affecting portability, reliability, scalability, and vendor lock-in. Possible solutions were proposed such as to come up with a mechanism of Mobile Agent-Based Open Cloud Computing Federation (MABOCCF) that uses a Mobile Agent that can migrate application code or data from one cloud computing service provider to another independently. Qi et al [14] discussed the comparison between key characteristics of mobile cloud computing and cloud computing, its features and challenges as well. Several mobile cloud computing architectures were reviewed such as CloneCloud and AlfredO. Various issues addressed about mobile cloud computing were similar to issues found in [12] and [13], with possible solutions proposed such as the use of virtualization and task migration to solve mobile device limitation issues, bandwidth upgrade to address network issues especially on Quality of Communication since mobile cloud computing utilizes wireless network, and also the use of elastic application based on device capability as a solution for divided application services. [14] Overall, the research on mobile cloud computing discusses how it will affect and become an advantage to the end-users and developers. Google Cloud Platform, for example, is used in Firebase that can be used by developers to develop applications on it [15]. Hence, this project is utilizing the use of Firebase in the development of the MyAPT application. It is found that mobile cloud computing consists of the cloud computing infrastructure provider serving mobile end-users and application developers via the Internet. Limitations discussed such as mobile cloud computing platforms were still limited, lack of standards and around limitations of mobile devices for cloud computing [12]. In a paper by Chetan et al [13], another detailed overview of mobile cloud computing was discussed. Challenges of mobile cloud computing were discussed, the issue found in Qureshi et al [12] about lack of standards were also discussed. Possible solutions were proposed such as to come up with a mechanism of Mobile Agent-Based Open Cloud Computing Federation (MABOCCF). Qi et al [14] discussed the comparison between key characteristics of mobile cloud computing and cloud computing, its features and challenges as well. Several mobile cloud computing architectures were reviewed such as CloneCloud and AlfredO. Possible solutions proposed such as the use of virtualization and task migration to solve mobile device limitation issues, bandwidth upgrade to address network issues especially on Quality of Communication since mobile cloud computing utilizes the wireless network, and also the use of elastic application based on device capability as a solution for divided application services [14]. Overall, the research about mobile cloud computing looked at how it will affect and become an advantage to the end-users and developers.

3) Mobile Push Notifications: Information needs to be disseminated for people to be aware and notified by it. Throughout the evolution of distributed communication technologies, many systems of information dissemination were proposed. One of them is a push system. Push system has existed since the early days of the Internet, whereby it is used in early browsers such as Netscape Navigator in 1992, and email. It is found that most of the information distributed on the Internet was 'pulled' by the client that requested it from the source. Concepts of push systems application were identified and found to be useful in the intra-company employee information system, and a stock ticker system. Components of push systems architecture were thoroughly analyzed in comparison to the traditional, client-server and event-based systems and as a result, it consists of publisher, and subscriber $(\mathrm{P} / \mathrm{S})$. The publisher is the one who creates the content to be published or broadcasted to subscribers who will receive the content. The main issues in the push systems were discussed such as issues in scalability, network traffic, security, authentication, e-commerce, and its usage in mobile environments. The component model of push systems were adopted as a basis for the Minstrel project, which is a pluggable push system that can be expanded [16]. Push systems were also later discussed, specifically how they work in the mobile context. In this paper, the Minstrel project's architecture model of publisher and subscriber $(\mathrm{P} / \mathrm{S})$ were taken as the basis for their work. Several scenarios of mobile push were analyzed, such as push systems on stationary users, nomadic users and mobile users. Stationary users, for example, use a fixed IP address to get the information that he or she subscribed. Nomadic users use different IP addresses at various locations. Mobile users are like nomadic users but they are using the service while in motion. Hence, mechanisms such as location management, content adaptation and presentation are important in order to fit in with mobile users' scenarios. Therefore, mobile push architecture was proposed to address the issues in mobile users' scenarios. The mobile push architecture consists of the application layer, service layer, communication layer and transport layer [17]. Narrowing to the cloud environment, another paper discussed device push messaging technologies available in the cloud for Android. The author agrees that the Minstrel's model of push systems with publisher/subscriber has some similarities to Google's Cloud to Device Messaging (C2DM). Several other cloud push messaging systems technologies available for Android were tested and compared with C2DM in terms of performance and stability, such as XMPP, Urban Airship, and Xtify. These push messaging systems are tested in the Google App Engine platform. The results show that XMPP performed the best in terms of response time and stability, with multiple messages that can be delivered in a short time. However, C2DM shows the best overall results if the messages are not sent in a huge amount in a short time [18]. In a later work by Yilmaz et al, the authors took a closer look at Google Cloud Messaging (GCM), which is the successor of C2DM. It is discussed that the results were only tested to send notifications from time to time to a single device, and not from a mass transmissions of push messages. Online and offline scenarios were taken into consideration for the test, and found that GCM is not suitable to be used in time-critical scenarios, and only suitable for general push messaging cast to multiple devices [19]. The mobile push notification system is taken into a business perspective, particularly e-commerce. Kumar et al suggested that notification is a quick way to notify customers in a business. 
It is discussed that there are several issues surrounding GCM, such as using http protocol, which cannot track the delivery of the notification and the action of the users on the notification. Thus, in this paper, they conducted a simulation of two push notification systems, which are GCM and Mosquitto (MQTT). The results show that MQTT performed better over http-based systems such as GCM, though initial connection test shows MQTT has slightly higher battery consumption than GCM. Hence, MQTT is suitable for business purposes as it deals with multiple notifications to be sent to customers that should be delivered reliably [20]. Mobile push notification is definitely a good way to engage with users to keep them notified of events anywhere and anytime. The model of publisher and subscriber is an essential component in mobile push systems. However, there is little research on how mobile push notifications can improve communication and information distribution in a residential community.

\section{B. Observation}

Observation is a method of collecting data based on examining real-world situations and events that will be useful for the development of a research or project. The observation was done by observing how the residents of a high-rise condominium (Sri Bahagia Court) receive information about happenings around the apartment complex and how the building management and residents committee disseminate information to the residents. Observation criteria were focused on the weaknesses in how the information was distributed to residents and its effect on them.

\section{Questionnaire}

The questionnaire is another method of collecting data and it can be widely distributed to people. The questionnaire set was done using online form creating a tool, Google Forms. It is then distributed to Facebook groups of high-rise building residents, particularly those in Sri Bahagia Court and Angkasa Condominium, and UCSI University network on CourseNetworking LMS platform. It was made clear that the respondents to the questionnaire must be residents of high-rise residential buildings. The development of questions was based on the literature materials which have been reviewed and similar type of research which has been conducted [1]-[3]. There are several parts in the questionnaire. The parts are as follows:

1) Demographics: The first part is to determine the general demographics of the respondents such as gender, age group, and nationality.

2) Device Type: The second part is to determine the type of mobile device used by the respondents, whether it is a smartphone or a regular mobile phone.

3) Smartphone details: If the respondents answered 'Smartphone' in the part on Device Type, the respondents are then asked about the operating system (OS) of the smartphone that they are using it on iOS, Android or another legacy mobile OS.

4) Residential details: Respondents are asked about ownership, that is whether they are the owner or renter of the unit. Respondents are also asked whether they are aware or join an online community group of their residential area. Online residential community group - This part is for Nononline - This part is for respondents who answered 'No' to whether they join the online community group for their apartment. They were asked how do they get information around their residential area. Likert scale question of 'Strongly Disagree" to "Strongly were also asked on whether they currently feel well informed about happenings around their residential area.

5) The Mobile App: The last part of the questionnaire mostly consists of questions with Likert scale answers of 1 "Strongly Disagree" to 5 "Strongly Agree". In this part, respondents were asked whether they agree that social media is not made for online residential communities, agree that a mobile app to notify happenings around their residential area would be a great idea, and agree that the mobile app will improve communications between the residents and the building's management. An optional question about other features to incorporate in the mobile app was asked.

\section{RESULTS AND DISCUSSION}

\section{A. Observation}

The observation was made in the middle-cost condominium Sri Bahagia Court, located in Cheras, Kuala Lumpur to find out how the residents receive information on happenings around the area, and how the management of the building and the residents' committee information to the residents.

The observation was recorded between 1 April and 15 July 2018. In April, a new information board was placed in front of the lift. Since then, the management seemed to be more proactive in displaying new announcements or notices to be read and made aware to the residents. However, there is also another noticeboard near the management's office that displays different content from the one at the lift. Having both noticeboards with different information might lead to confusion and misinformation among the residents.

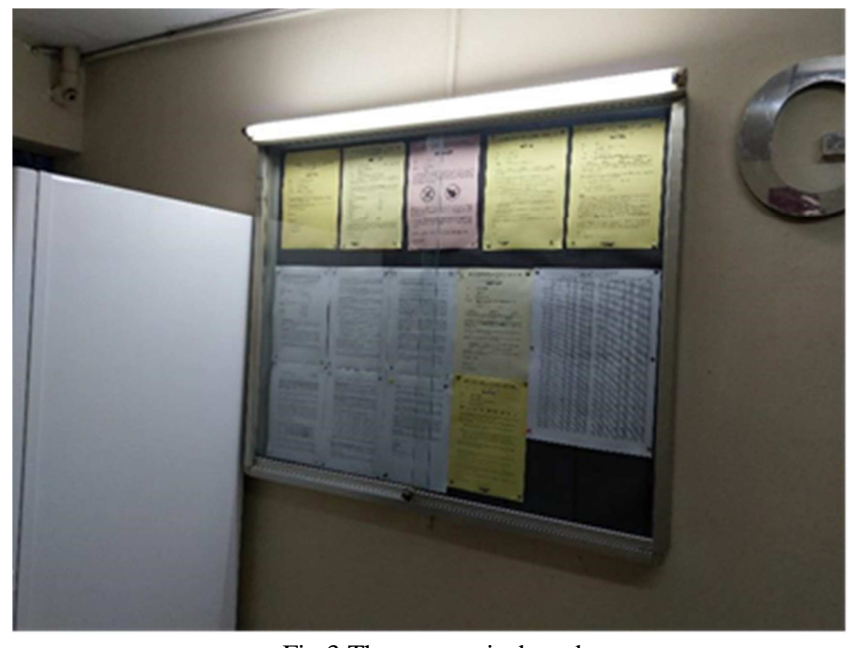

Fig. 3 The new noticeboard

During the end of June, the management had put up on the information board a grass-cutting schedule of 5 days from 25 to 29 of June, separated in zones. However, it is observed that the grass cutting process was not following the planned 
zones and this caused inconvenience to the residents, especially car owners who had to park their car away from the zone. An incident of car damage due to the unexpected change in the grass cutting schedule was reported by one of the residents in the Sri Bahagia Court's Facebook group.
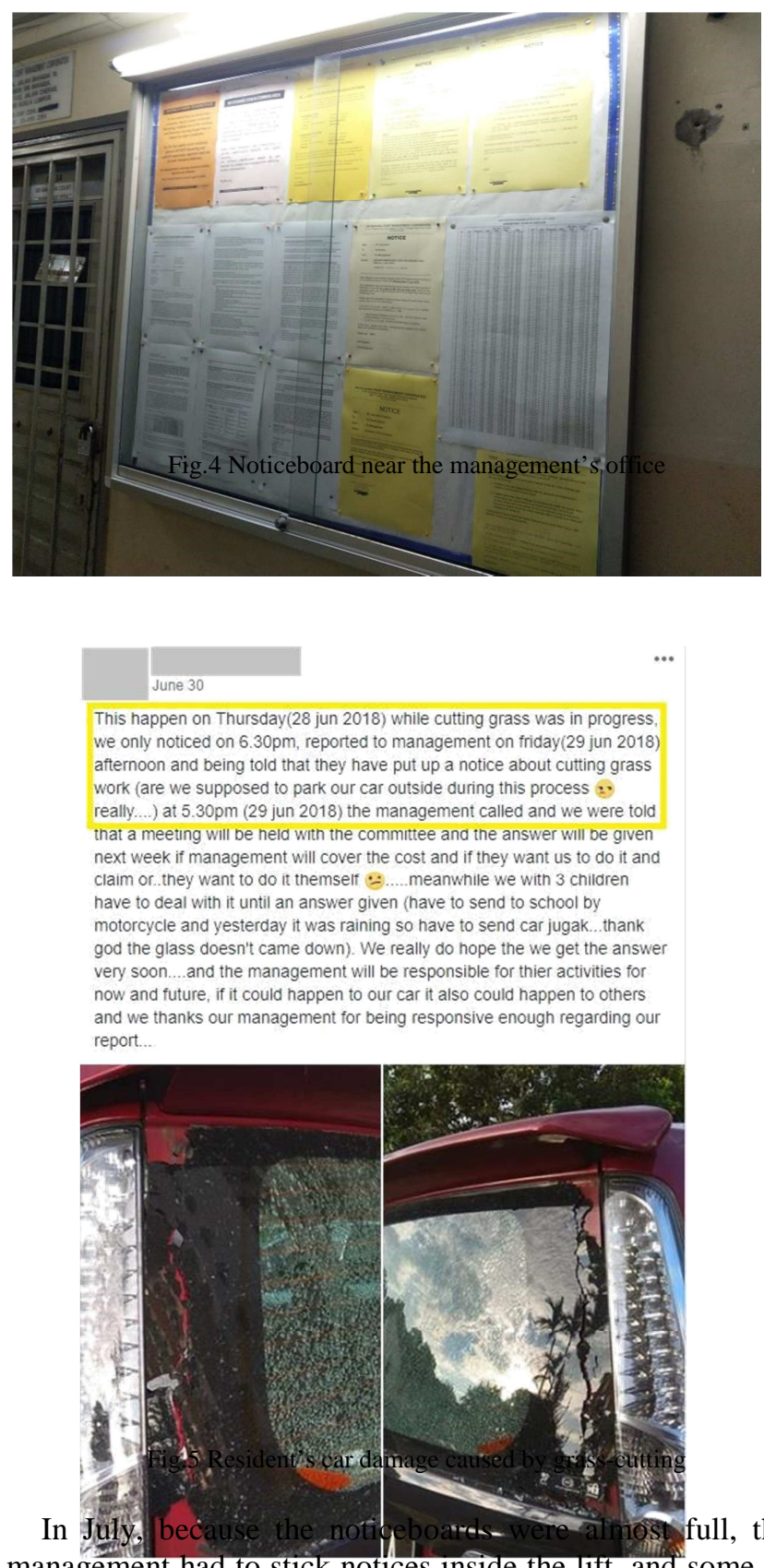

full, the management had to stick notices inside the lift, and some of the notices were vandalized. The Facebook group, which is managed by the residents' committee members, must work hard in addressing issues experienced by the residents while it should be the management's job to take care of things. From all the data gathered from the observation, most of the residents receive information about happenings in their area from the information board that is managed by the management. However, due to inconsistencies and unreliability of the notices made by the management, it caused inconvenience to the residents.

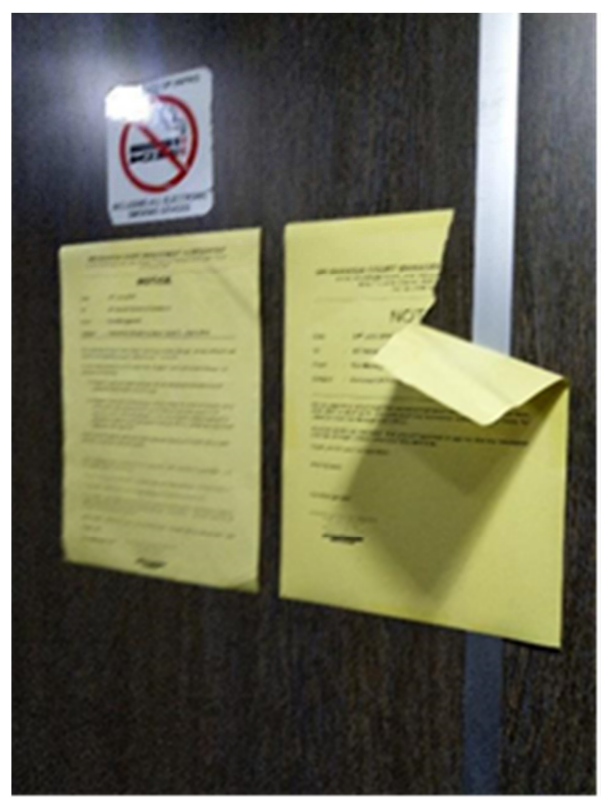

Fig.6 Torn notices

\section{B. Questionnaire}

The questionnaire was distributed online to Facebook groups of residents of high-rise residential buildings, particularly Sri Bahagia Court and Angkasa Condominium, and UCSI University network on Course Networking platform. The questionnaire gathered 41 respondents in total. The following results are selected based on the objectives of this study.

Aside from this online group, how do you get information about happenings around your residential area?
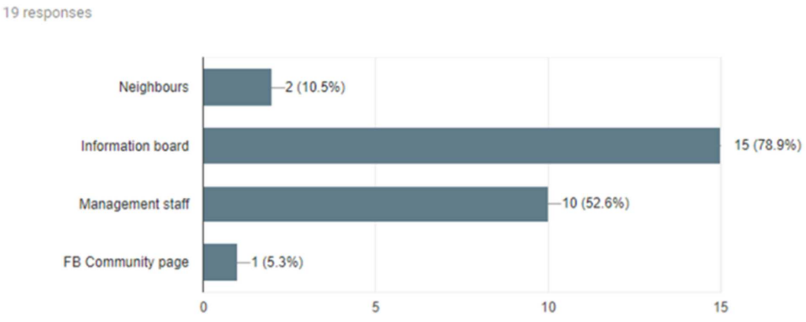

Fig.7 Respondents who joined online residential community group

In this part, 19 respondents who joined the online residential community group were asked how do respondents get information about the happenings around their residential area other than in the online group. As shown in the bar chart in Fig.7, it shows that they got information mostly from the information board, followed by management staff, and neighbors. 
How do you get information about happenings around your residential area?

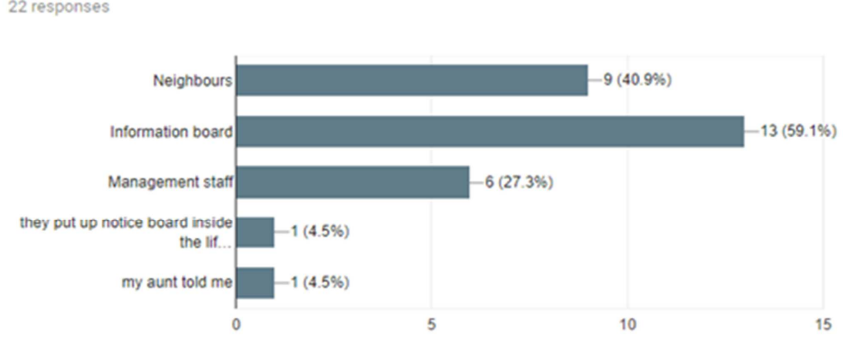

Fig.8 Respondents who did not join any online residential community group (non-online)

This part was for 22 respondents who did not join the online residential community group. They were asked how do respondents get information about the happenings around their residential area. As shown in the bar chart in Fig.8, once again, it shows that they got information mostly from the information board, followed by neighbors and management staff.

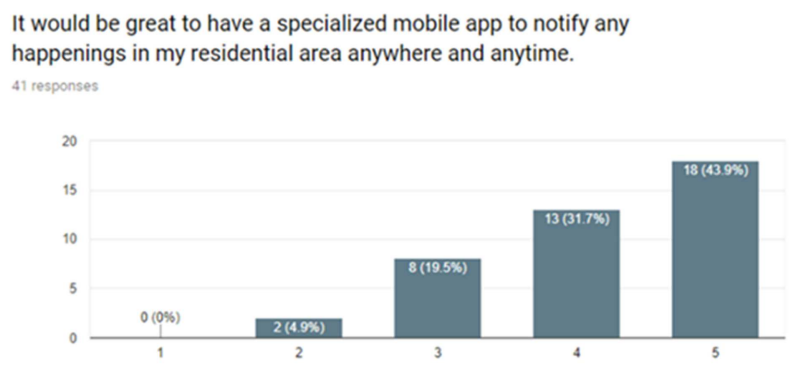

Fig.9 The idea of mobile app for apartment residents

This part is about whether the respondents agree to having a specialized mobile app to notify happenings around their residential area. By using a Likert scale of 1 - 'Strongly Disagree' to 5 'Strongly Agree', out of 41 responses, 18 respondents chose 5, 13 respondents chose 4,8 respondents chose 3 , and 2 respondents chose 2 . None of the respondents chose 1 .

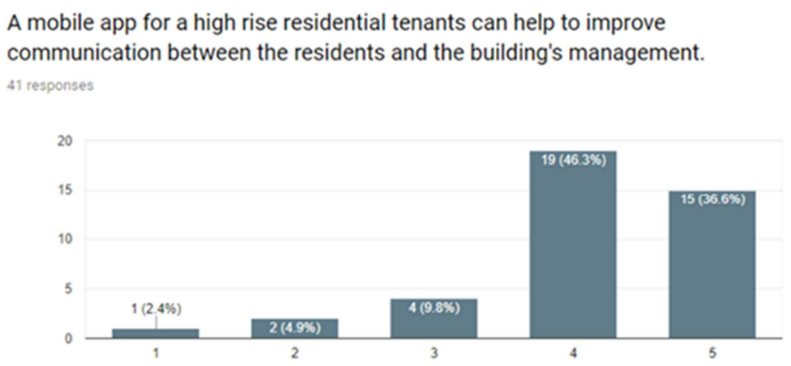

Fig.10 Respondents' sentiment about the effectiveness of the mobile app in improving the communication between the residents and the building's management

This part is about the respondents' sentiment about the effectiveness of the mobile app in improving the communication between the residents and the building's management. By using a Likert scale of 1 - 'Strongly Disagree' to 5 'Strongly Agree', out of 41 responses, 19 respondents chose 4, 15 respondents chose 5, 4 respondents chose 3, 2 respondents chose 2, and 1 respondent chose 1 .

From the results in the previous section, it is shown that most of the residents of a high-rise residential building were depending on the information board to get information about happenings around their residential area. It is also proven that many of the residents agree with the idea to have a specialized mobile app to notify them about the happenings around their residential area and agree on its potential to improve communication between the residents and the building's management. Therefore, with all these insightful responses from the respondents, there is a need to develop a mobile pp for apartment residents.

\section{CONCLUSIONS}

Communication between the residents and the management of high-rise residential buildings is essential to ensure the convenience of both parties and the satisfaction of the residents when the building is taken care of to provide a healthy living environment. Based on the research conducted, residents of high-rise apartments need mobile applications for communications among residents as well as with the management of the apartment. Besides, they also want to get notification of updated information via mobile phones. Hence, developing a mobile app such as Android or iOS for apartment residents would be useful for both management and residents of high-rise apartments.

\section{REFERENCES}

[1] S. R. H. A. Wahab, A. I. C. Ani, A. Sairi, N. M. Tawil and M. Z. A. Razak, "Classification of High-Rise Residential Building Facilities: A Descriptive Survey on 170 Housing Scheme in Klang Valley," in MATEC Web of Conferences, 2016.

[2] N. M. Tawil, Y. M. Yusoff, A. I. Che-Ani, N. A. G. Abdullah and M. Surat, "A Study of Management Corporation Financial in High Rise Residential with Correlation of Management Fund and Facilities Provided," International Business Management, vol. 6, pp. 304-307, 2012.

[3] S. R. H. Abd-Wahab, A. Sairi, A. I. Che-Ani, N. M. Tawil and S. Johar, "Building Maintenance Issues: A Malaysian Scenario for High Rise Residential Buildings," International Journal of Applied Engineering Research, vol. 10, pp. 15759-15776, 2015.

[4] D. Chell, T. Erasmus, S. Colley and O. Whitehouse, The mobile application hacker's handbook, John Wiley \& Sons, 2015.

[5] Facebook, "Facebook Newsroom | Stats," [Online]. Available:https://newsroom.fb.com/company-info/\#statistics.

[6] T. D. Baruah, "Effectiveness of Social Media as a tool of communication and its potential for technology enabled connections: A micro-level study," International Journal of Scientific and Research Publications, vol. 2, pp. 1-10, 2012.

[7] N. Park, K. F. Kee and S. Valenzuela, "Being immersed in social networking environment: Facebook groups, uses and gratifications, and social outcomes," CyberPsychology $\backslash \&$ Behavior, vol. 12, pp. 729-733, 2009.

[8] C. Madge, J. Meek, J. Wellens and T. Hooley, "Facebook, social integration and informal learning at university: 'It is more for socialising and talking to friends about work than for actually doing work'," Learning, media and technology, vol. 34, pp. 141-155, 2009.

[9] C.-H. Chou and S.-M. Pi, "The effectiveness of Facebook groups for e-learning," International Journal of Information and Education Technology, vol. 5, p. 477, 2015.

[10] M. M. Yunus and H. Salehi, "The effectiveness of Facebook groups on teaching and improving writing: Students' perceptions," International Journal of Education and Information Technologies, vol. 1, pp. 87-96, 2012.

[11] N. S. Ping and M. Maniam, "The Effectiveness of Facebook Group Discussions on Writing Performance: A Study in Matriculation 
College.," International Journal of Evaluation and Research in Education, vol. 4, pp. 30-37, 2015.

[12] S. S. Qureshi, T. Ahmad, K. Rafique and others, "Mobile cloud computing as future for mobile applications-Implementation methods and challenging issues," in Cloud Computing and Intelligence Systems (CCIS), 2011 IEEE International Conference on, 2011.

[13] S. Chetan, G. Kumar, K. Dinesh, K. Mathew and M. A. Abhimanyu, "Cloud computing for mobile world," available at chetan. ueuo. com, 2010.

[14] H. Qi and A. Gani, "Research on mobile cloud computing: Review, trend and perspectives," in Digital Information and Communication Technology and it's Applications (DICTAP), 2012 Second International Conference on, 2012.

[15] N. Singh, "Study of Google Firebase API for Android," International Journal of Innovative Research in Computer and Communication Engineering, vol. 4, pp. 16738-16743, 2016.
[16] M. Hauswirth and M. Jazayeri, "A component and communication model for push systems," in ACM SIGSOFT Software Engineering Notes, 1999.

[17] I. Podnar, M. Hauswirth and M. Jazayeri, "Mobile push: Delivering content to mobile users," in Distributed Computing Systems Workshops, 2002. Proceedings. 22nd International Conference on, 2002.

[18] J. Hansen, T.-M. Gr\{\o\}nli and G. Ghinea, "Towards cloud to device push messaging on Android: Technologies, possibilities, and challenges," International Journal of Communications, Network and System Sciences, vol. 05, no. 12, pp. 839-849, 2012., 2012.

[19] Y. S. Yilmaz, B. I. Aydin, and M. Demirbas, "Google cloud messaging (GCM): An evaluation," in Global Communications Conference (GLOBECOM), 2014 IEEE, 2014.

[20] A. Kumar and S. Johari, "Push notification as a business enhancement technique for e-commerce," in Image Information Processing (ICIIP), 2015 Third International Conference on, 2015. 